RMD

Open

Rheumatic \&

Musculoskeletal Diseases

\title{
Atlas for the OMERACT thumb base osteoarthritis MRI scoring system (TOMS)
}

Féline P B Kroon, ${ }^{1}$ Charles G Peterfy, ${ }^{2}$ Philip G Conaghan, ${ }^{3}$ Violaine Foltz, ${ }^{4}$ Frédérique Gandjbakhch, ${ }^{4}$ Iris Eshed, ${ }^{5}$ Harry K Genant, ${ }^{6,7}$ Mikkel Østergaard, ${ }^{8,9}$ Monique Reijnierse, ${ }^{10}$ Johan L Bloem, ${ }^{10}$ Ida K Haugen, ${ }^{11}$ Margreet Kloppenburg ${ }^{1,12}$

To cite: Kroon FPB, Peterfy CG, Conaghan $\mathrm{PG}$, et al. Atlas for the OMERACT thumb base osteoarthritis MRI scoring system (TOMS). RMD Open 2018;4:e000583. doi:10.1136/ rmdopen-2017-000583

- Prepublication history for this paper is available online. To view these files, please visit the journal online (http://dx.doi. org/10.1136/rmdopen-2017000583)

Received 21 September 2017 Revised 28 November 2017 Accepted 1 December 2017

\section{ABSTRACT}

This paper presents an atlas for the Outcome Measures in Rheumatology Clinical Trials (OMERACT) thumb base osteoarthritis MRI scoring system (TOMS). The atlas includes reference images of each grade of each feature that is assessed in TOMS (synovitis grade $0-3$, subchondral bone defects grade $0-3$, osteophytes grade $0-3$, cartilage assessment grade $0-3$, subluxation and bone marrow lesions grade $0-3$ ) in the first carpometacarpal and scapho-trapezio-trapezoid joint. The presented reference images can be used to guide scoring of thumb base MRls in patients with hand osteoarthritis according to the OMERACT TOMS.

Hand OA affects the interphalangeal and thumb base joints, including the CMC-1 and STT joints. Much is still unknown about the pathophysiology of thumb base OA. Although MRI studies have led to more insights in interphalangeal OA, thumb base MRI studies are still lacking. To facilitate this, recently the first MRI scoring system for thumb base OA was developed by the OMERACT MRI Working Group, the TOMS. ${ }^{1}$

Representative examples of each grade of the different features that are assessed in the TOMS are presented (see table 1 for definitions and scaling of each feature). Images from patients with hand OA were obtained from the Hand Osteoarthritis in Secondary Care (HOSTAS) study at Leiden University Medical Center (Leiden, The Netherlands). Images were acquired on a $1.5 \mathrm{~T}$ extremity MRI unit (ONI, GE, Wisconsin, USA). Examples of synovitis evaluated on contrast-enhanced images were obtained from patients with hand OA from the Nor-Hand study at Diakonhjemmet Hospital (Oslo, Norway) and were acquired on a 1.5 T MRI unit (Siemens Aera, Germany) after administration of gadolinium contrast. Example images were selected by a single reader with experience in using the TOMS and subsequently approved by three experienced radiologists (of which one is also experienced in using the score).
Check for updates

For numbered affiliations see end of article.

Correspondence to

Féline P B Kroon;

f.kroon.reum@lumc.nl 
Table 1 Definitions and scaling of features in proposed OMERACT TOMS

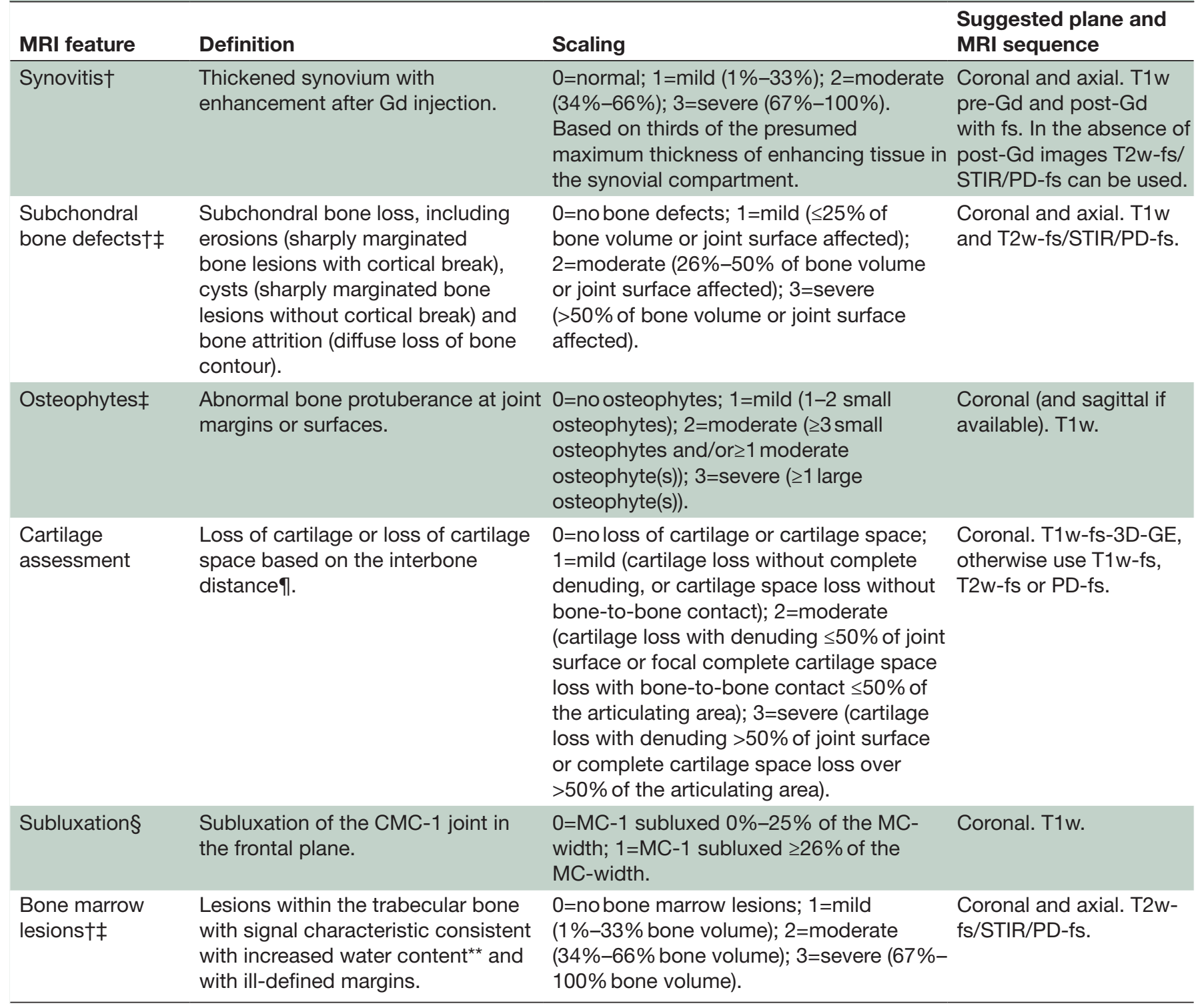

Table was reprinted with permission from Kroon et al. ${ }^{1}$ All rights reserved.

†In longitudinal studies, 0.5 increments can be included to indicate within-grade change in synovitis, subchondral bone defects and bone marrow lesions.

‡Proximal and distal parts of joint are scored separately for subchondral bone defects, osteophytes and bone marrow lesions.

§Only the CMC-1 joint is evaluated for this feature.

IIf assessment of cartilage and cartilage space are in conflict, direct visualisation of the cartilage should be prioritised.

**High signal intensity on STIR/T2w-fs images.

CMC-1, first carpometacarpal; fs, fat saturated; Gd, gadolinium-based contrast agent; GE, gradient echo; MC-1, first metacarpal; PD, proton density; OA, osteoarthritis; OMERACT, Outcome Measures in Rheumatology Clinical Trials; STIR, Short T1 Inversion Recovery; STT, scapho-trapezio-trapezoid; TOMS, thumb base OA MRI scoring system; w, weighted.

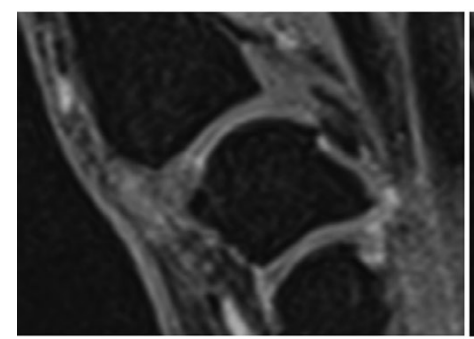

Normal

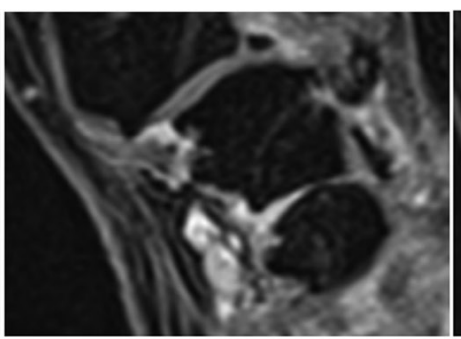

Grade 1

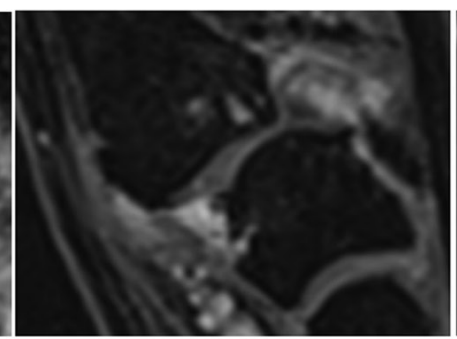

Grade 2

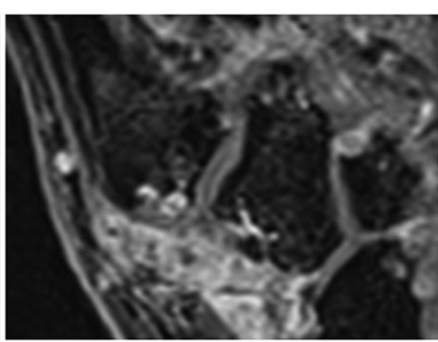

Grade 3

Synovitis first carpometacarpal ( $\mathrm{T} 1$ weighted-fat saturated postcontrast images). 


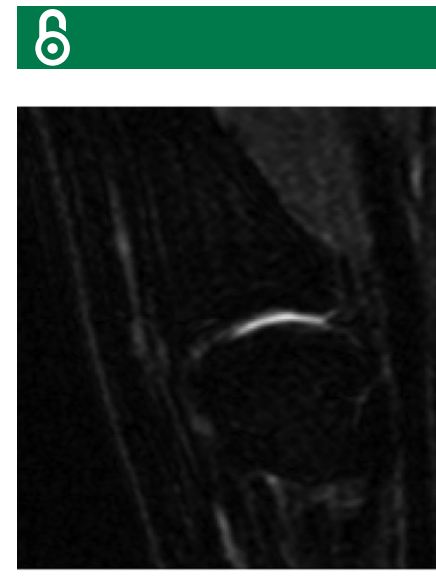

Normal

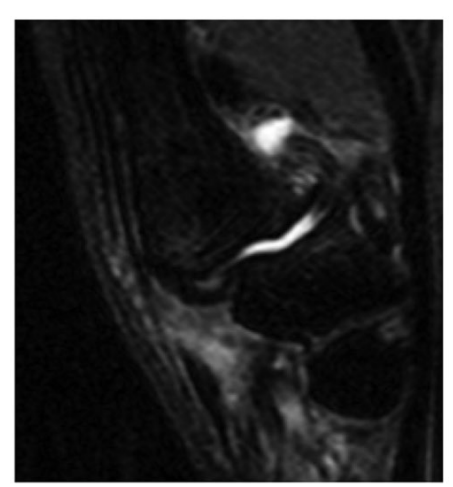

Grade 1

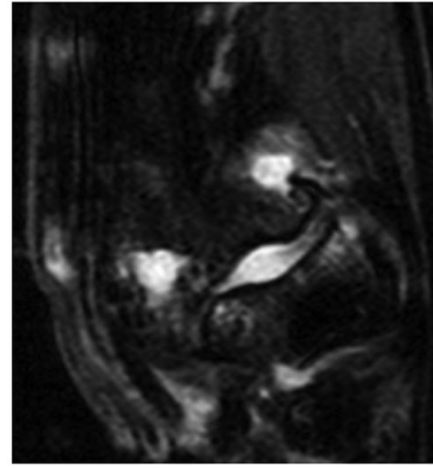

Grade 2

Synovitis first carpometacarpal (T2 weighted-fat saturated images).
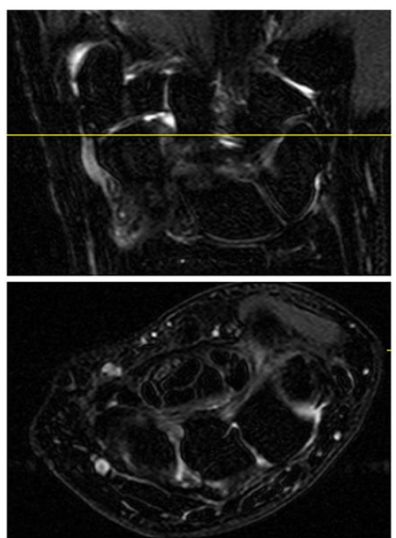

Normal
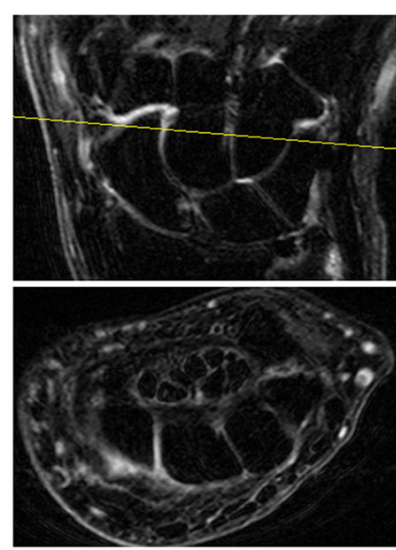

Grade 1

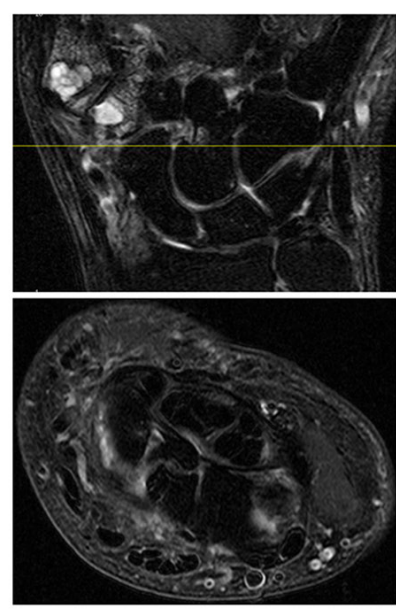

Grade 2

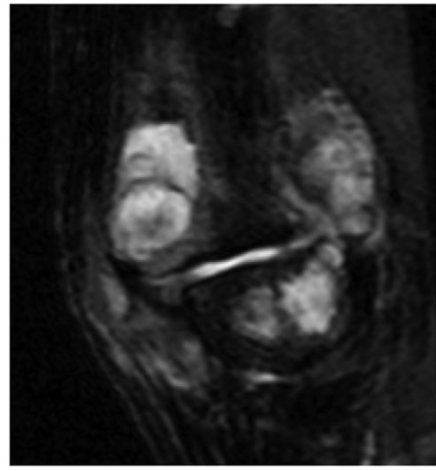

Grade 3

Subchondral bone defects first carpometacarpal: proximal first metacarpal (T1 weighted and T2 weighted-fat saturated images).

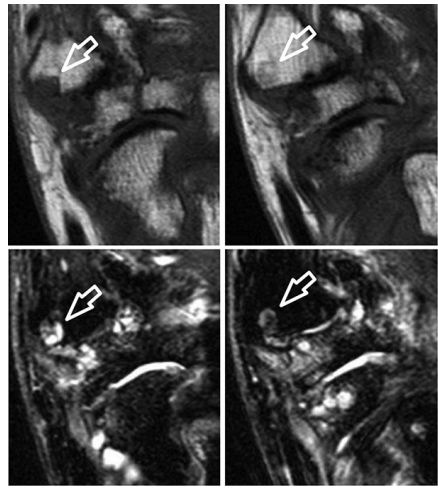

Grade 1

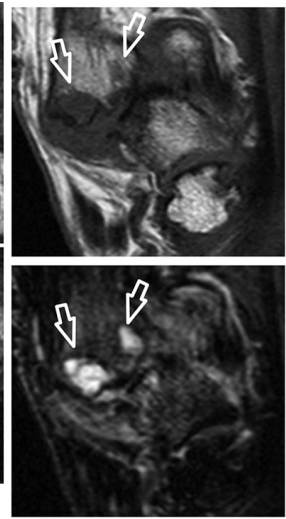

Grade 2
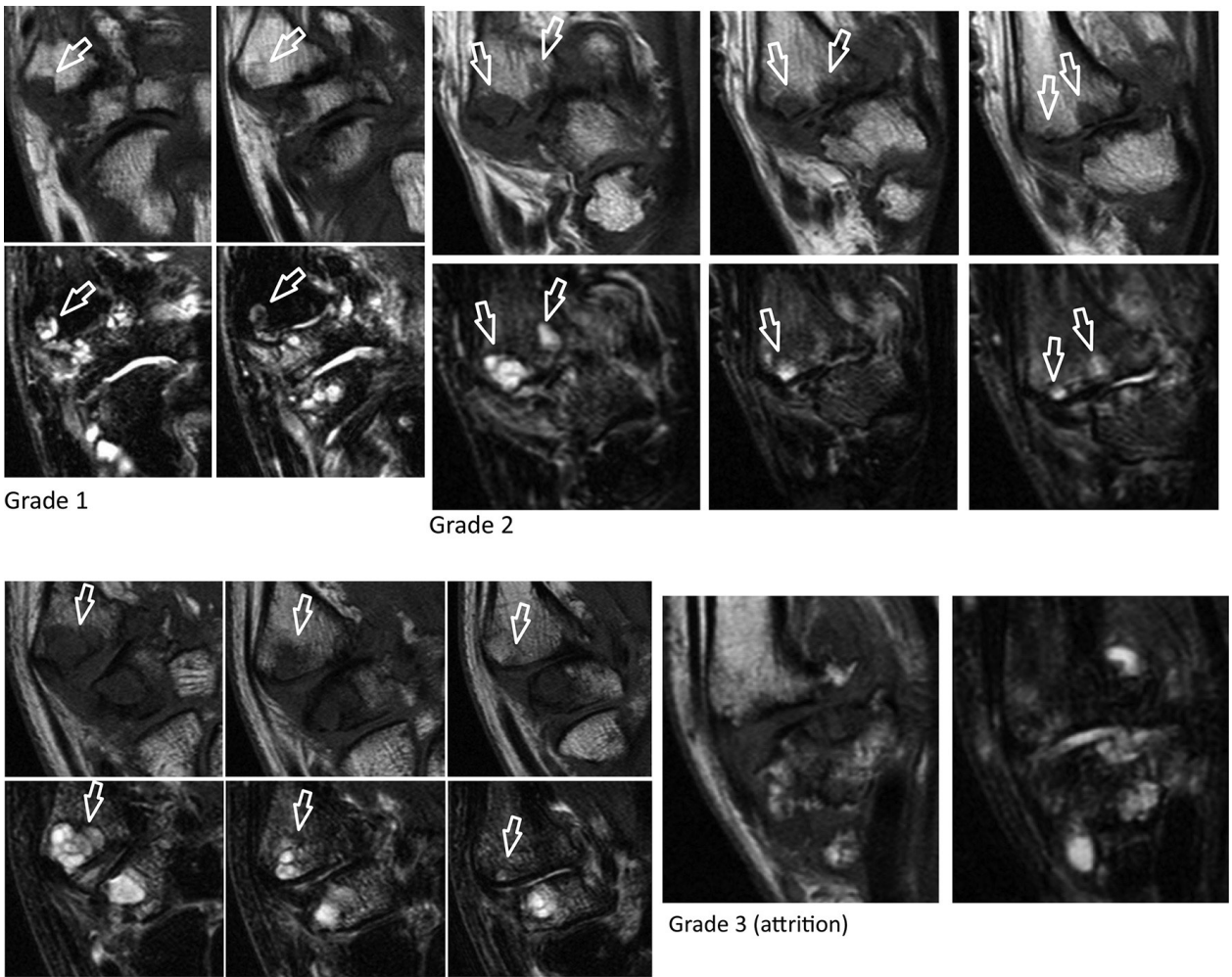

Grade 3 (attrition)
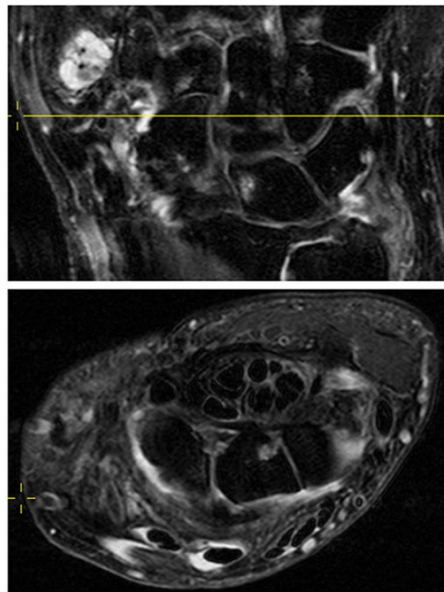

Grade 3 

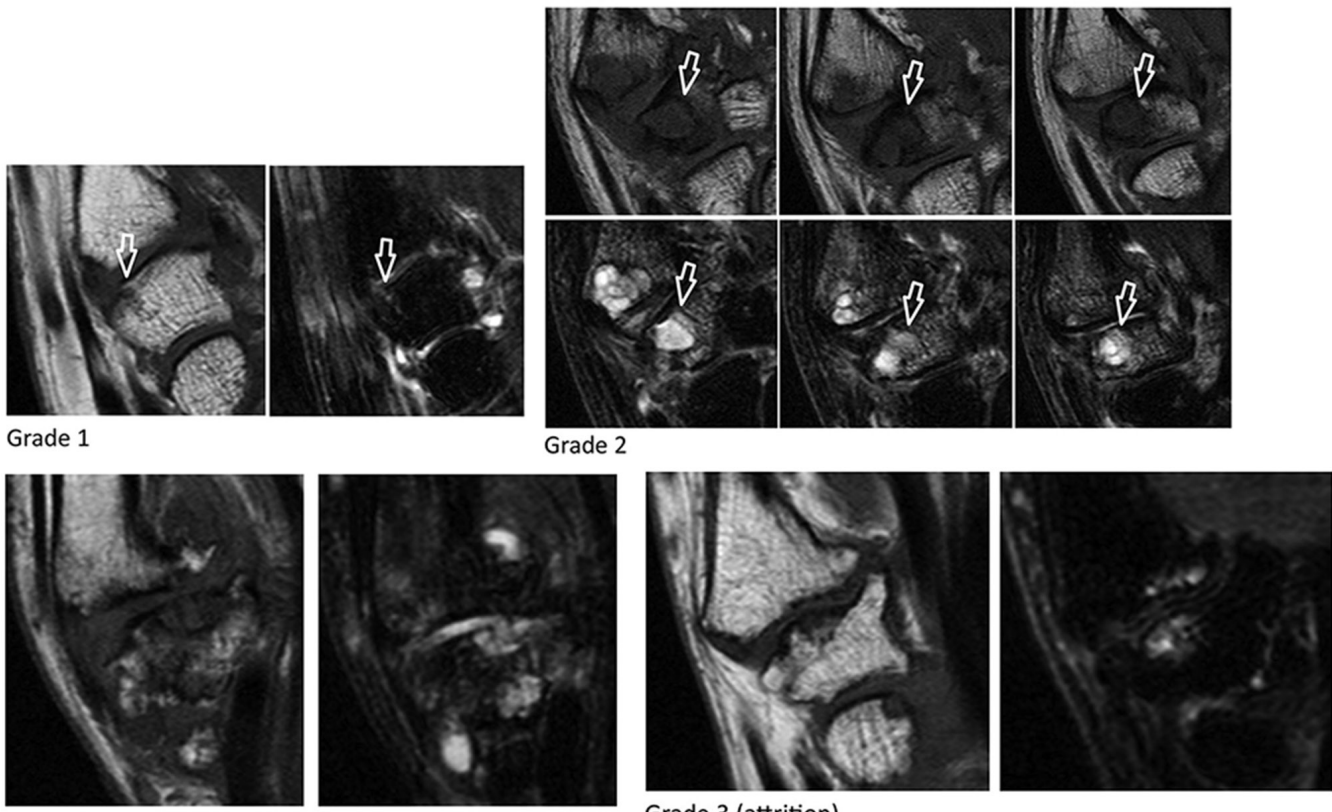

Grade 3

Grade 3 (attrition)

Subchondral bone defects first carpometacarpal: distal trapezium (T1 weighted and T2 weighted-fat saturated images).

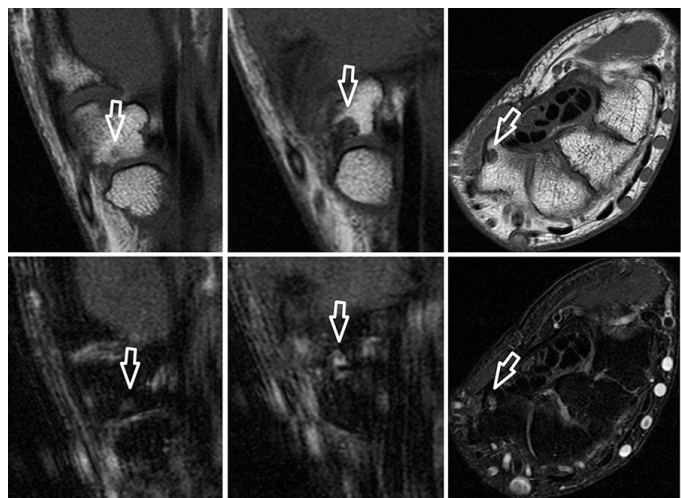

Grade 1

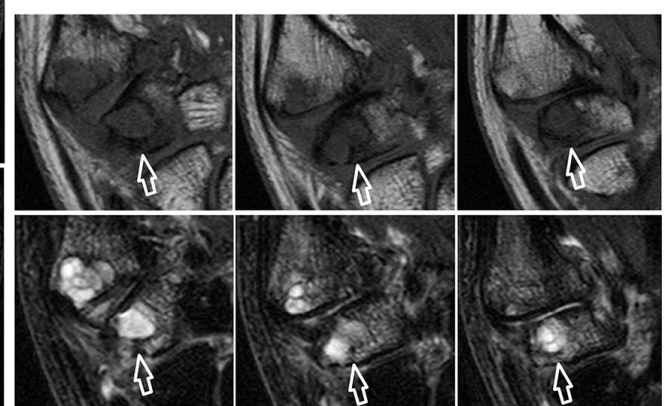

Grade 2

Subchondral bone defects scapho-trapezio-trapezoid: proximal trapezium (T1 weighted and T2 weighted-fat saturated images).

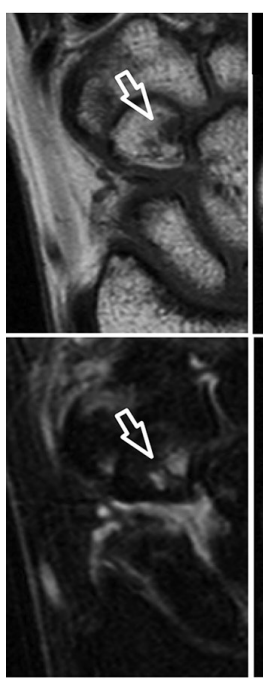

Grade 1

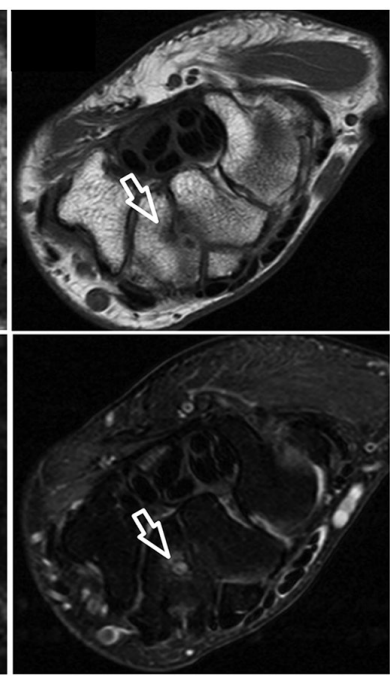

Grade 2

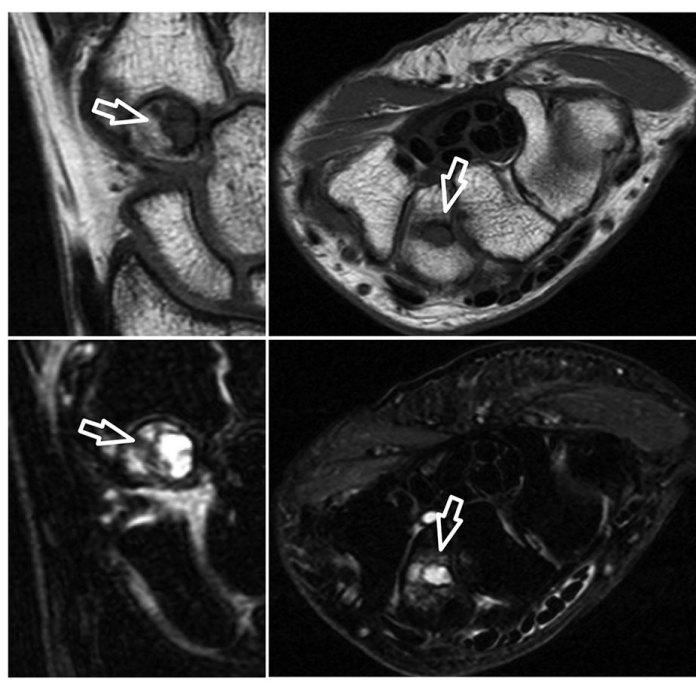

Subchondral bone defects scapho-trapezio-trapezoid: proximal trapezoid (T1 weighted and T2 weighted-fat saturated images). 


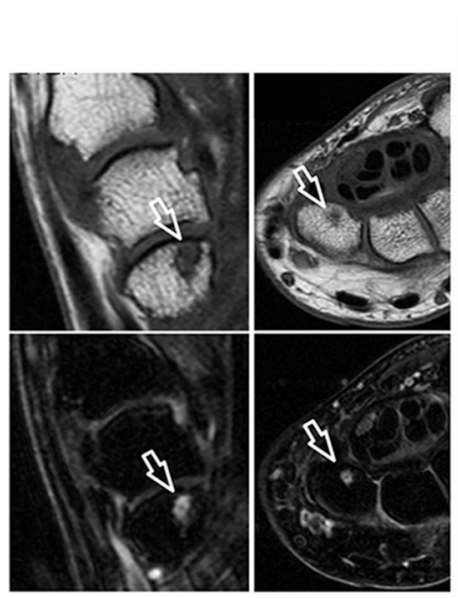

Grade 1

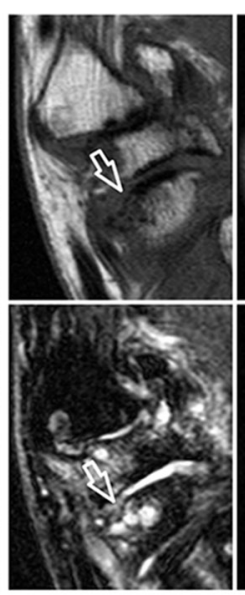

Grade 2

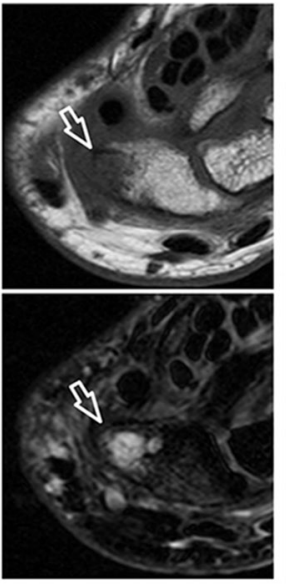

Grade 3

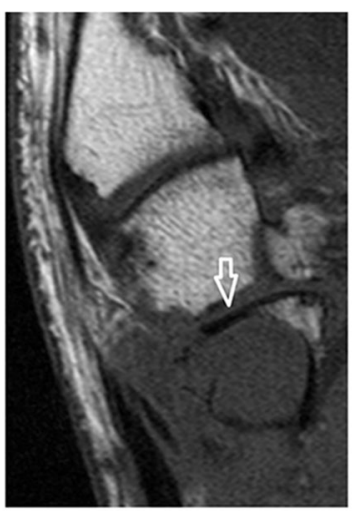

Subchondral bone defects scapho-trapezio-trapezoid: distal scaphoid (T1 weighted and T2 weighted-fat saturated images).

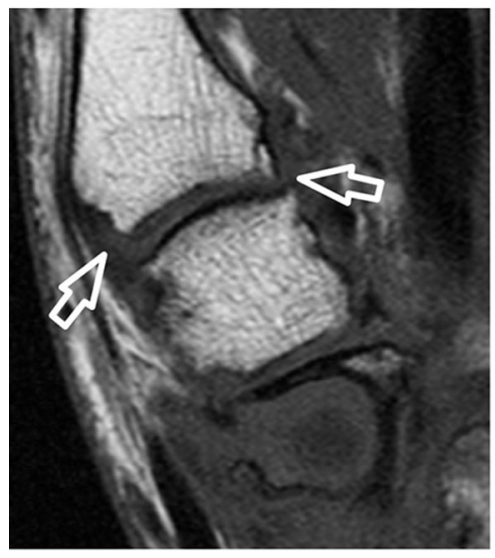

Grade 1

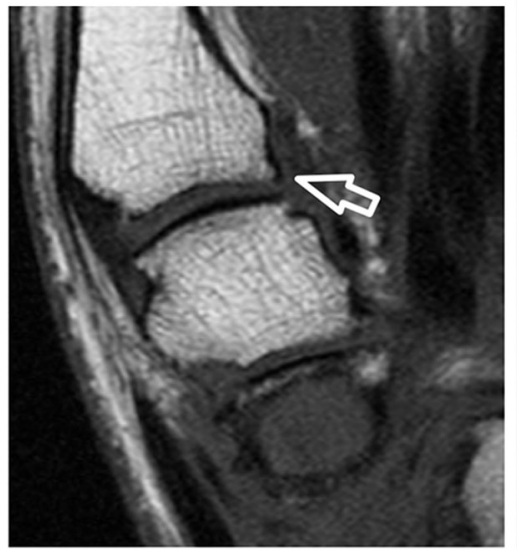

Grade 2
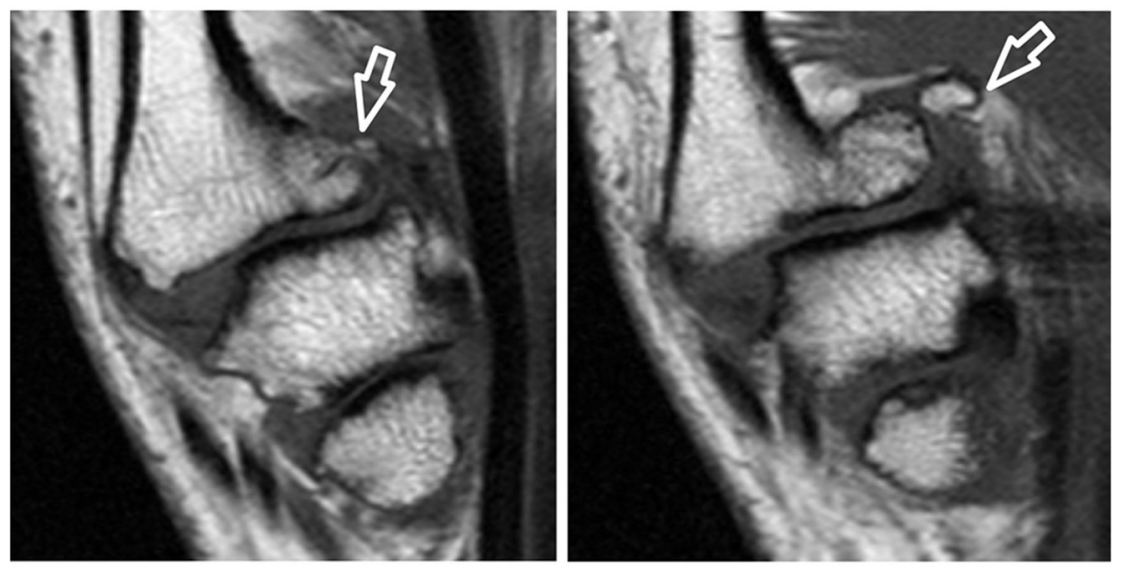

Grade 3

Osteophytes first carpometacarpal: proximal first metacarpal (T1 weighted images).
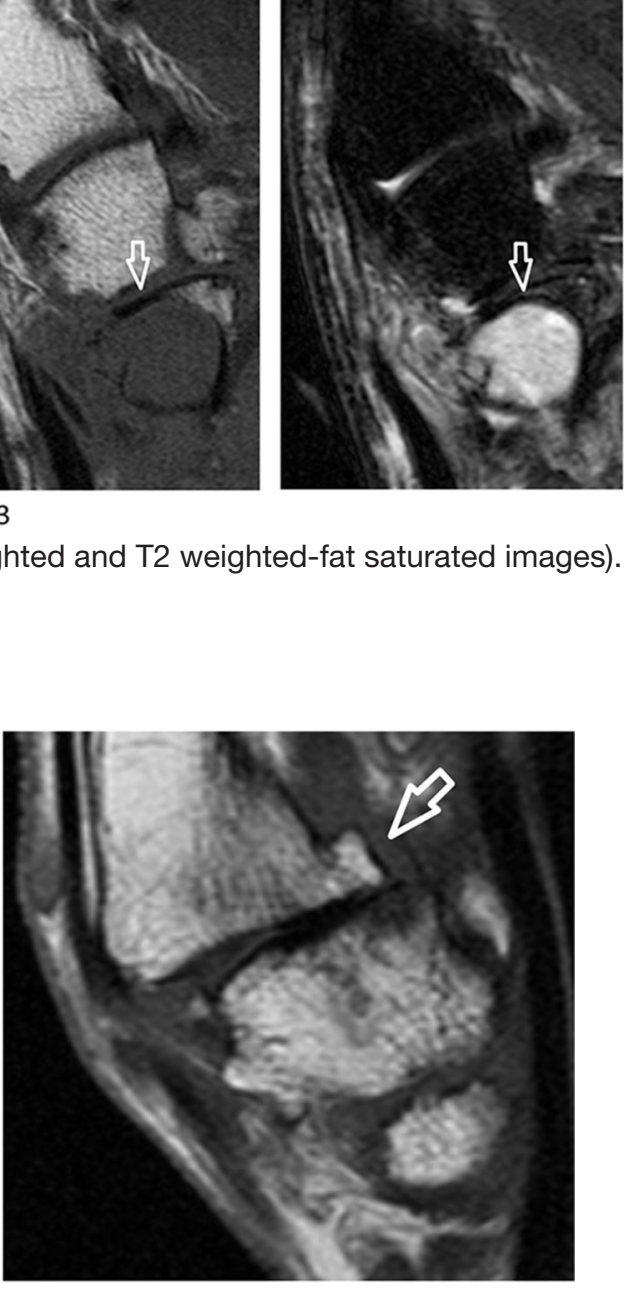


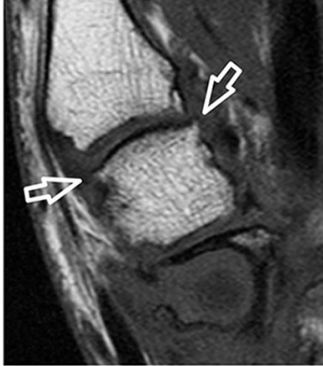

Grade 1
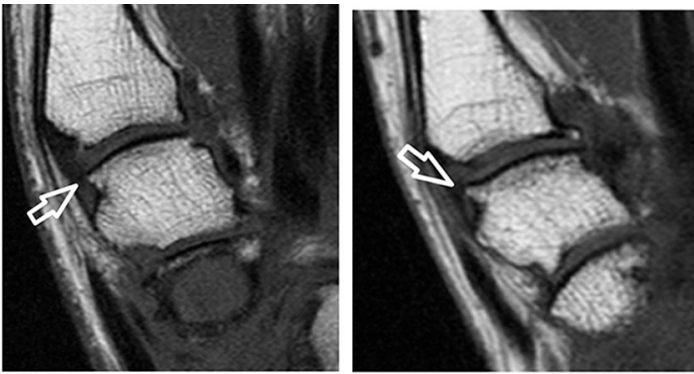

Grade 2

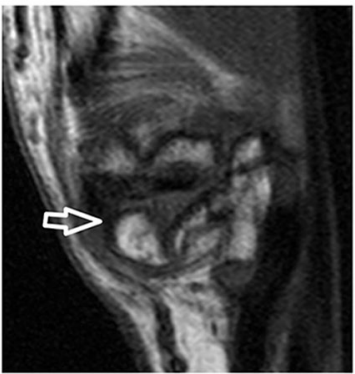

Grade 3

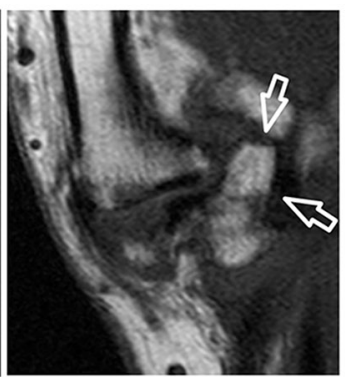

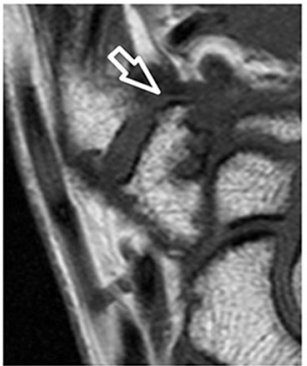
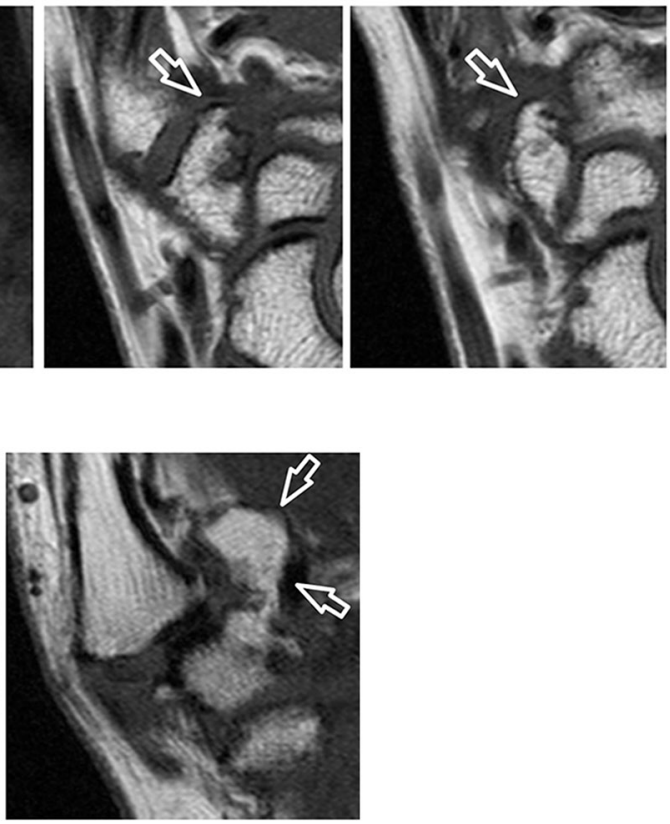

Osteophytes first carpometacarpal: distal trapezium (T1 weighted images).
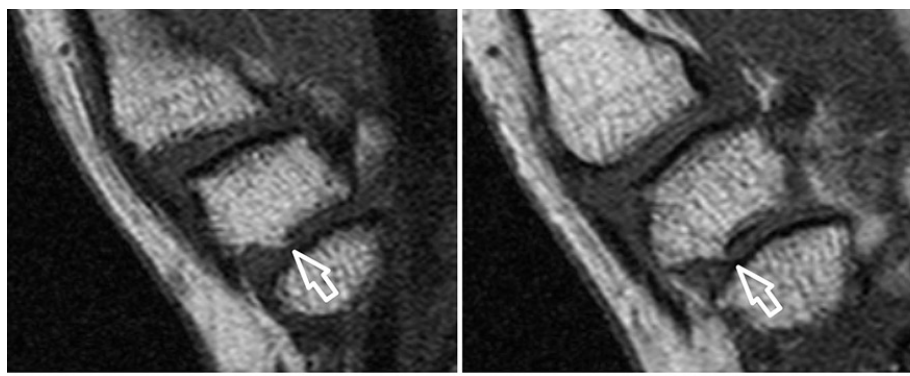

Grade 1

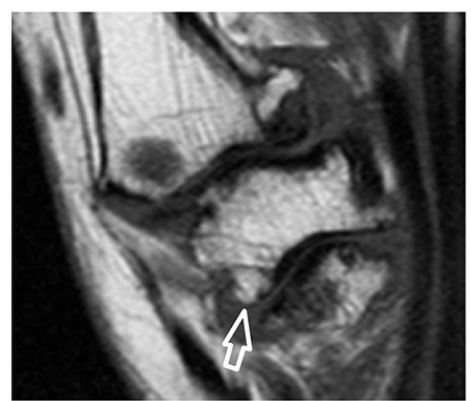

Grade 2
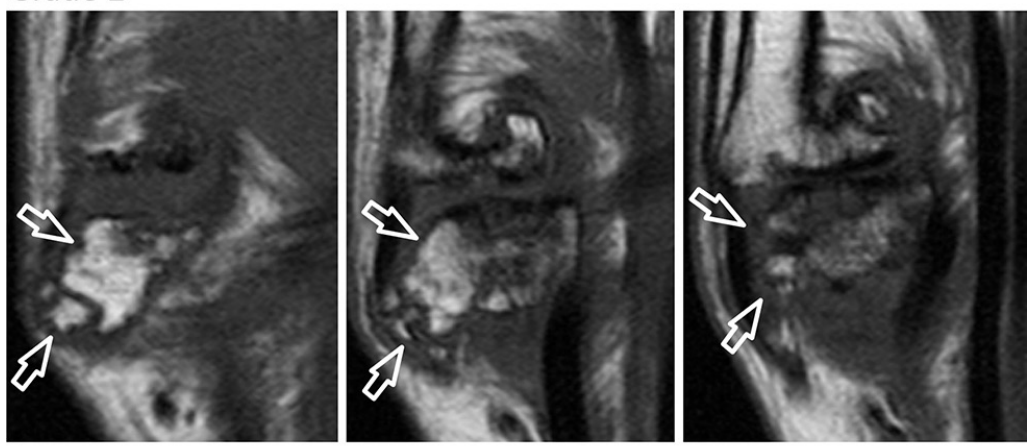

Grade 3

Osteophytes scapho-trapezio-trapezoid: proximal trapezium (T1 weighted images). 


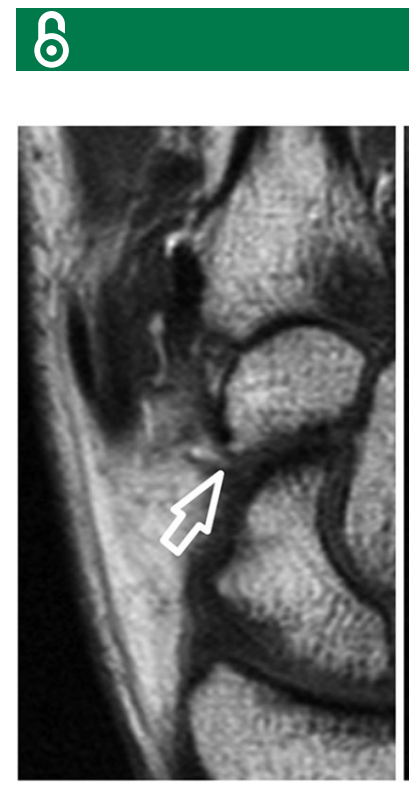

Grade 1

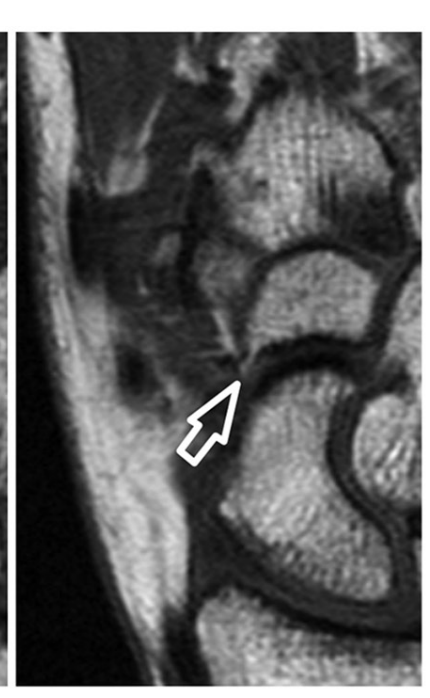

Grade 2

Osteophytes scapho-trapezio-trapezoid: proximal trapezoid (T1 weighted images).

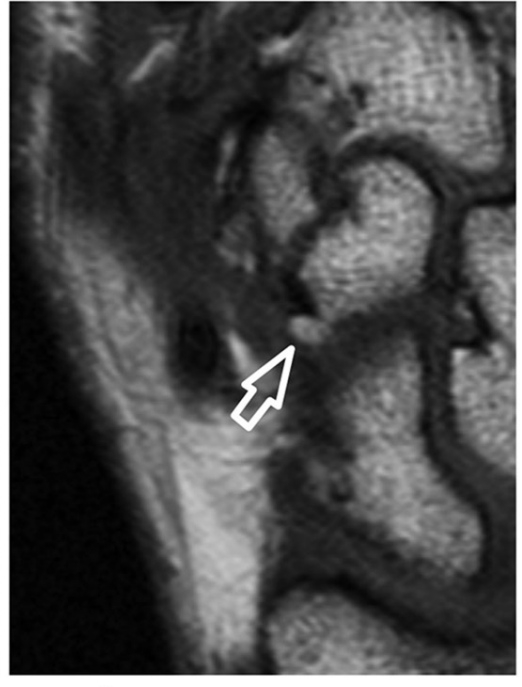

Grade 3

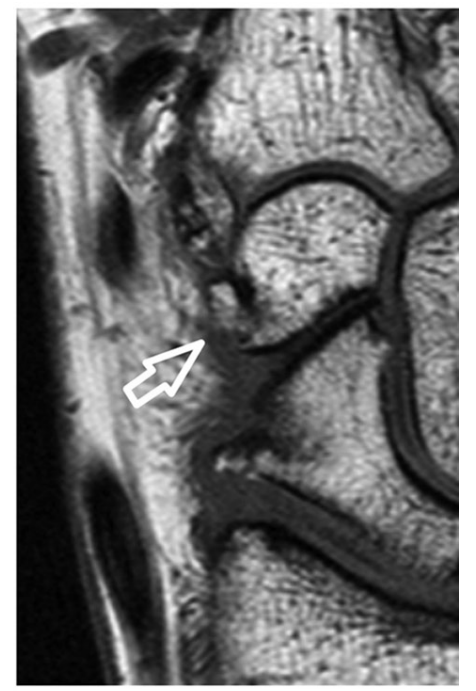

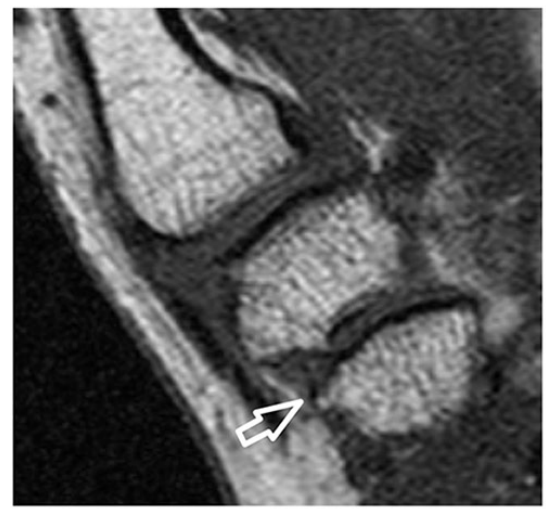

Grade 1

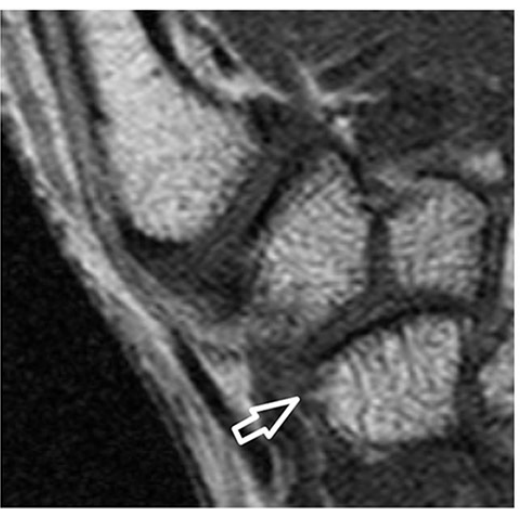

Grade 2

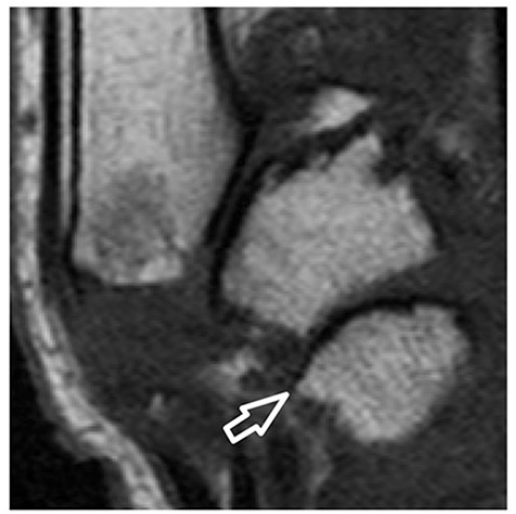

(5)

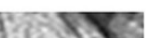

Grade 3

Osteophytes scapho-trapezio-trapezoid: distal scaphoid (T1 weighted images). 


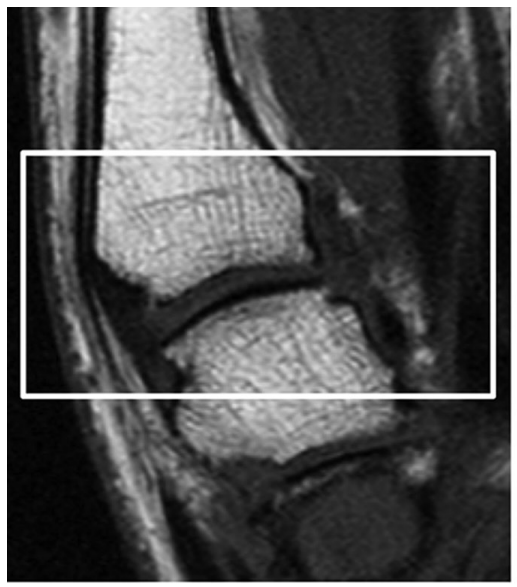

Normal

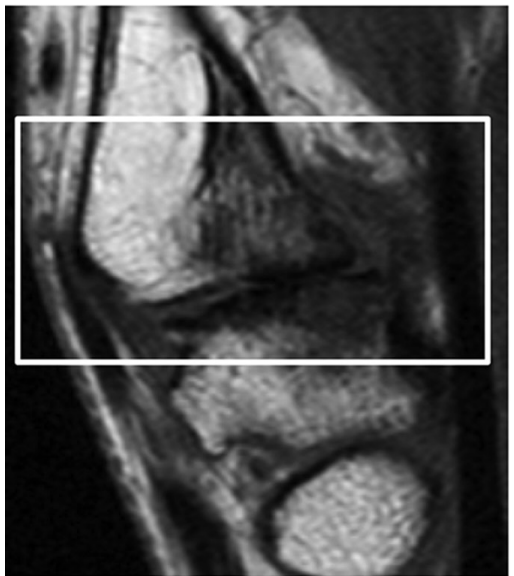

Grade 2

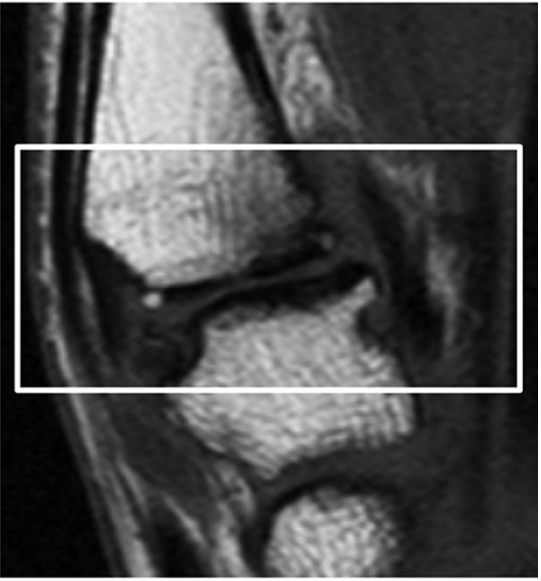

Grade 1

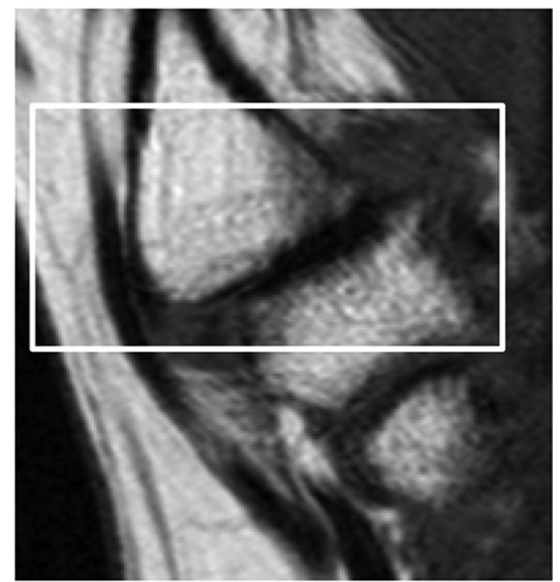

Grade 3

Cartilage assessment first carpometacarpal (T1 weighted images).

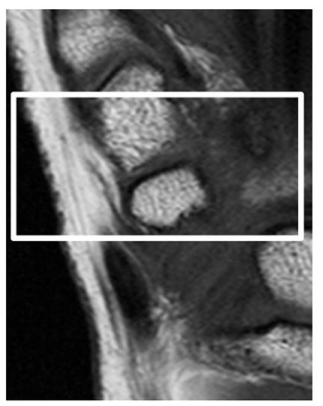

Normal
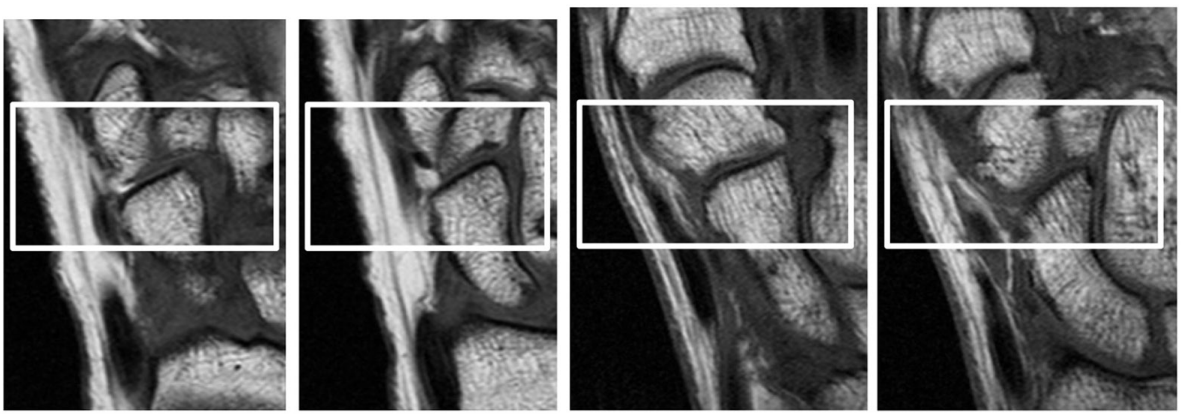

Grade 1

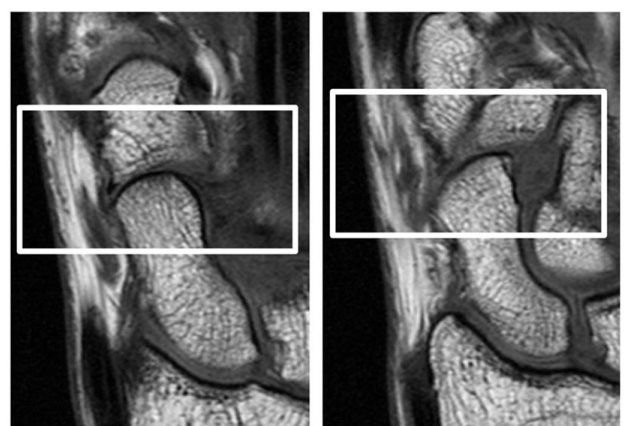

Grade 2

sment scap
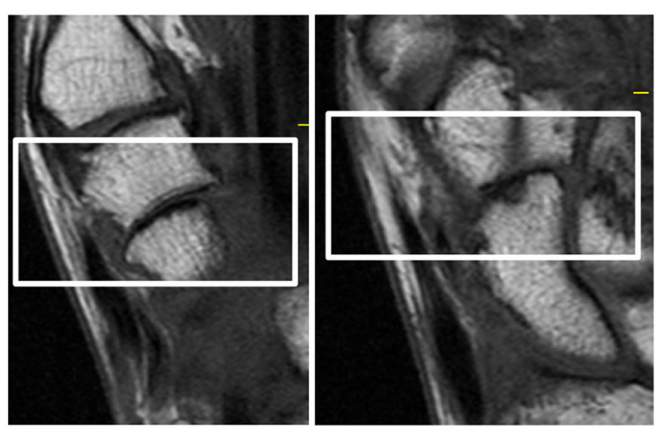

Grade 3 


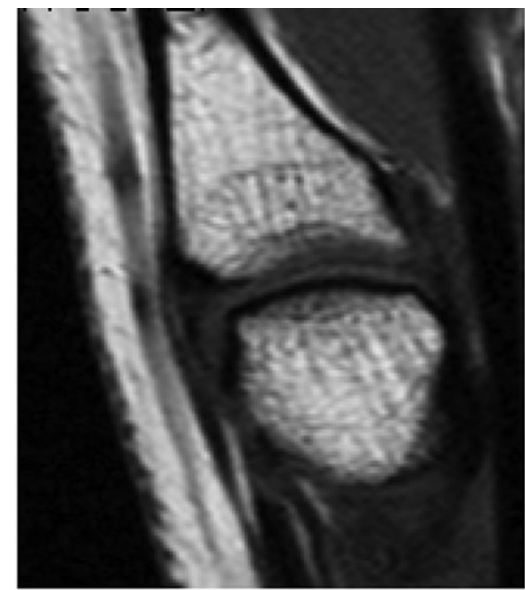

Normal

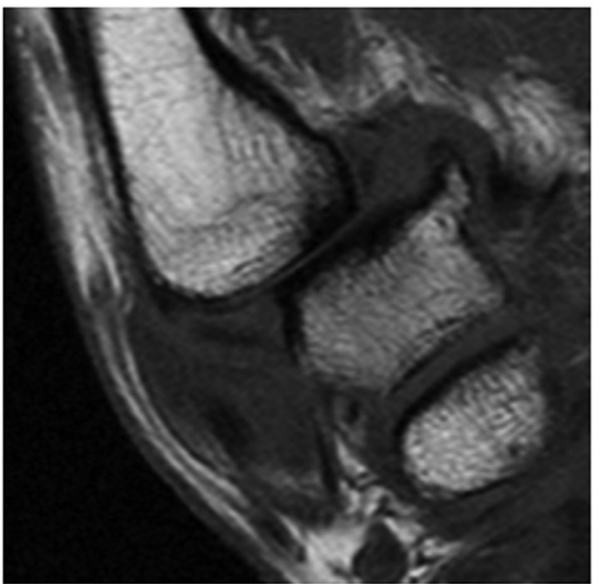

Subluxation present

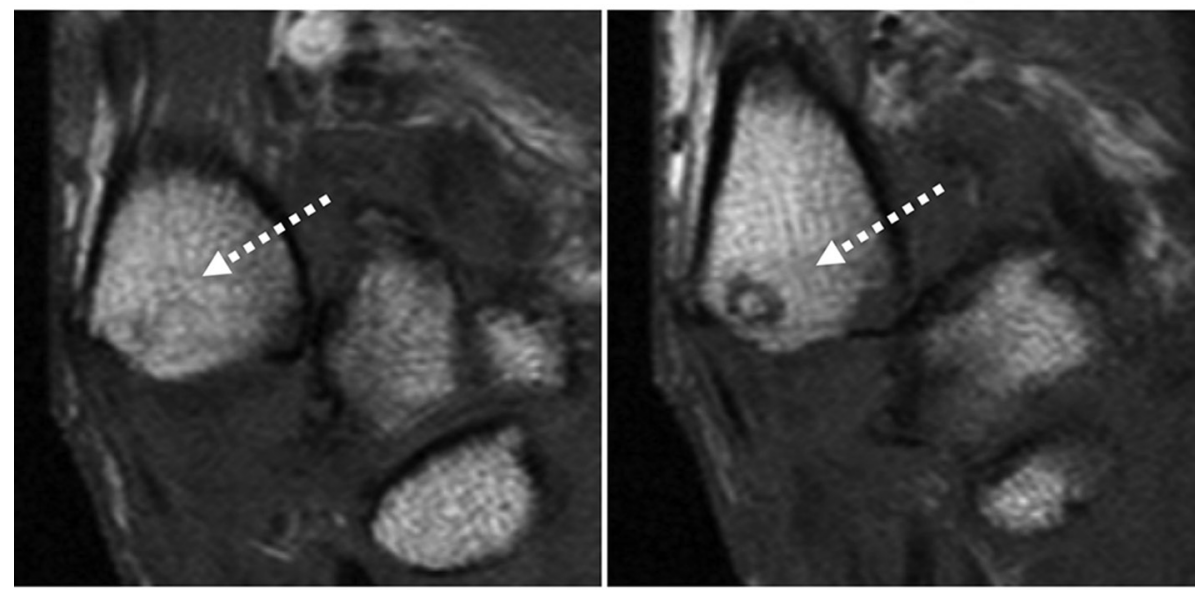

Subluxation present (severe)

[arrow points into direction of subluxation]

Subluxation first carpometacarpal (T1 weighted images).

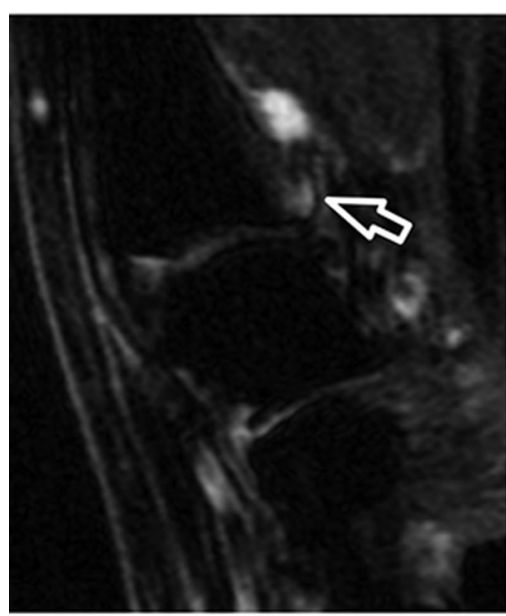

Grade 1

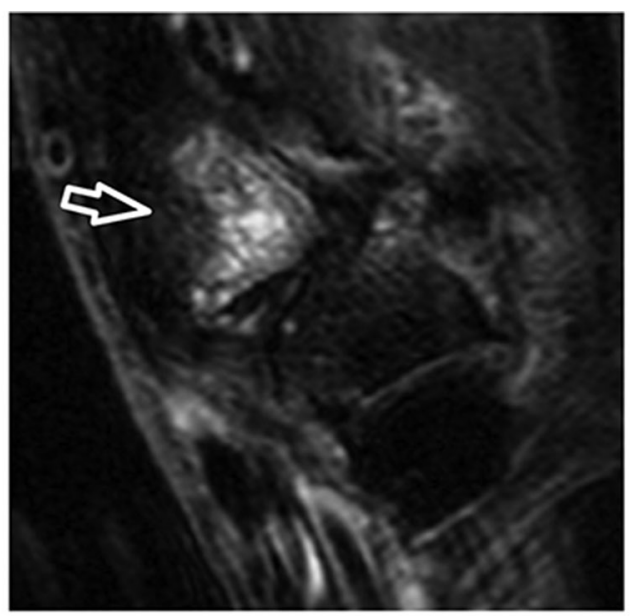

Grade 2

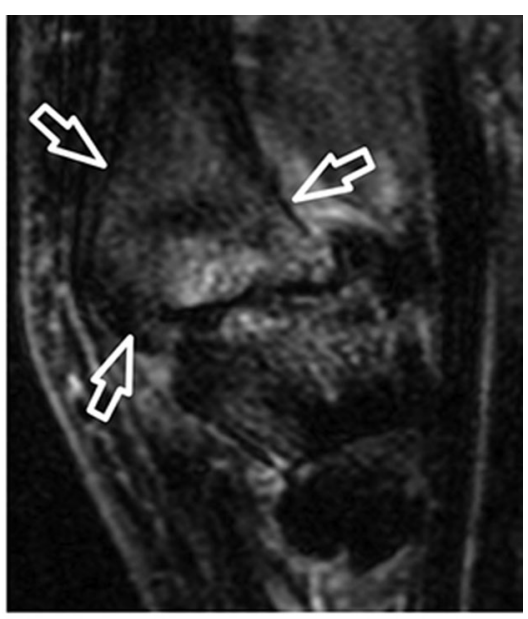

Grade 3

Bone marrow lesions first carpometacarpal: proximal first metacarpal (T2 weighted-fat saturated images). 

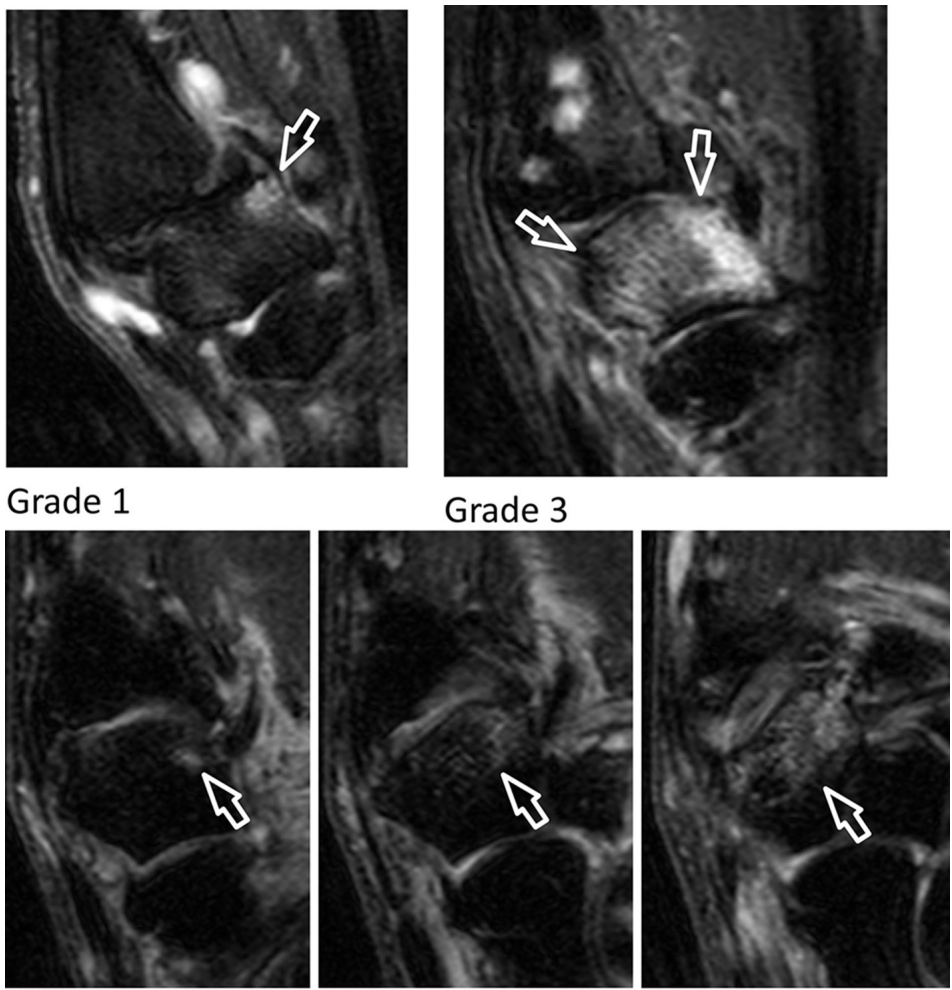

Grade 2

Bone marrow lesions first carpometacarpal: distal trapezium (T2 weighted-fat saturated images).

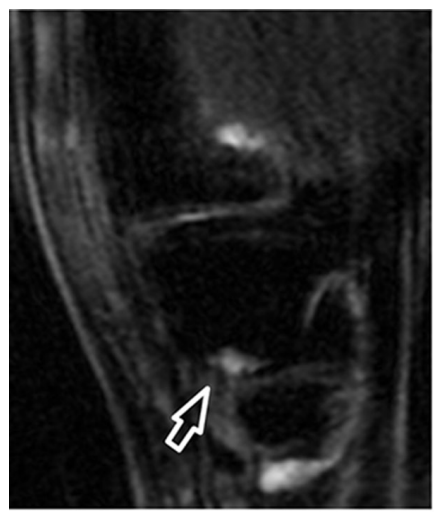

Grade 1

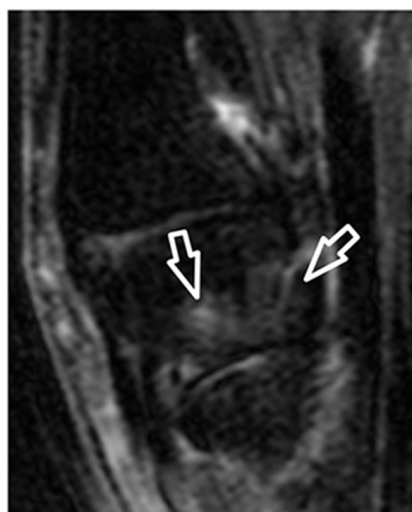

Grade 2

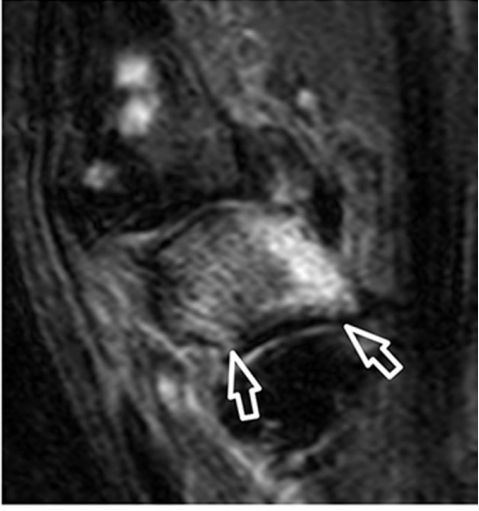

Grade 3

Bone marrow lesions scapho-trapezio-trapezoid: proximal trapezium (T2 weighted-fat saturated images).

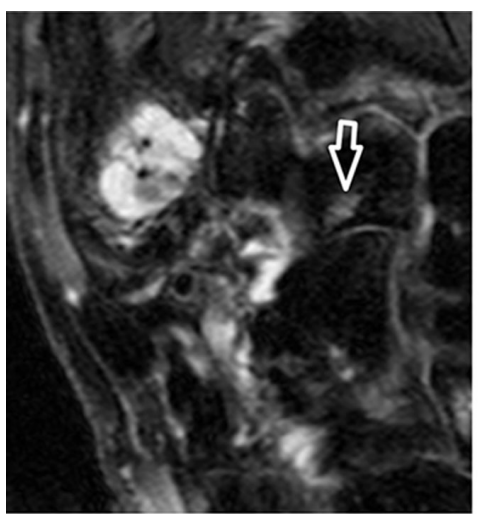

Grade 1

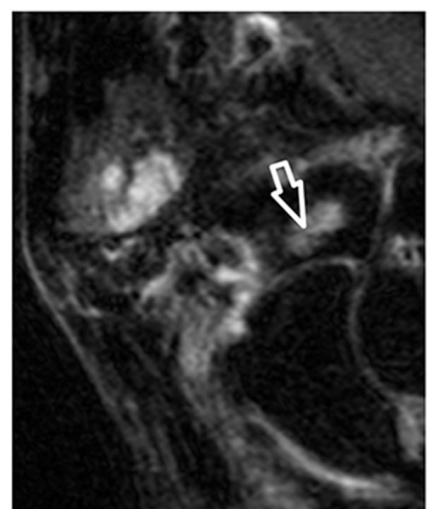

Grade 2

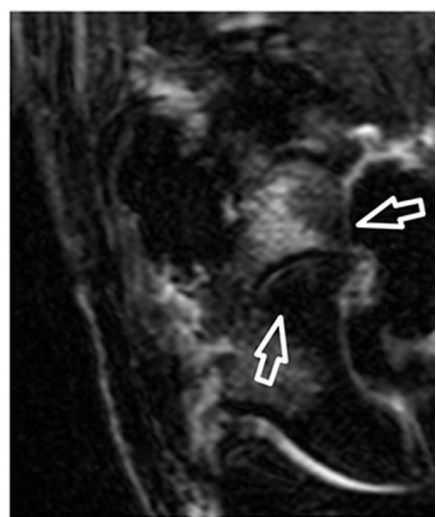

Grade 3

Bone marrow lesions scapho-trapezio-trapezoid: proximal trapezoid (T2 weighted-fat saturated images). 

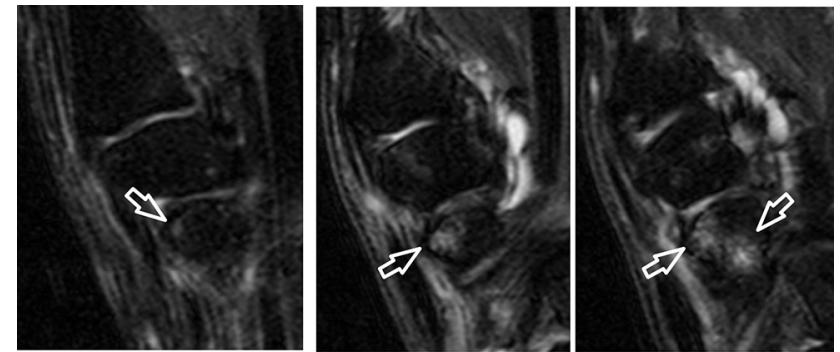

Grade 1

Grade 2

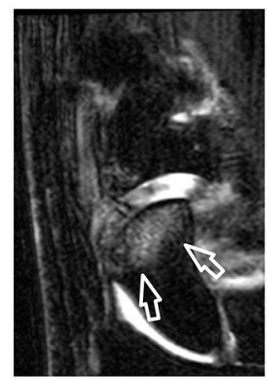

Grade 3

Bone marrow lesions scapho-trapezio-trapezoid: distal scaphoid (T2 weighted-fat saturated images).

\section{Author affiliations}

${ }^{1}$ Department of Rheumatology, Leiden University Medical Center, Leiden, The Netherlands

${ }^{2}$ Spire Sciences Inc, Boca Raton, Florida, USA

${ }^{3}$ Leeds Institute of Rheumatic and Musculoskeletal Medicine, University of Leeds and National Institute for Health Research, Leeds Biomedical Research Centre, Leeds, UK

${ }^{4}$ Department of Rheumatology, Pitié Salpêtriere Hospital, APHP, Université Pierre et Marie Curie, Paris, France

${ }^{5}$ Department of Diagnostic Imaging, Sheba Medical Center, Tel Aviv University, Tel Aviv, Israel

${ }^{6}$ Department of Radiology, University of California San Francisco, San Francisco, California, USA
${ }^{7}$ Department of Medicine, University of California San Francisco, San Francisco, California, USA

${ }^{8}$ Copenhagen Center for Arthritis Research, Center for Rheumatology and Spine Diseases, Glostrup Hospital, Copenhagen, Denmark

${ }^{9}$ Department of Clinical Medicine, University of Copenhagen, Copenhagen, Denmark

${ }^{10}$ Department of Radiology, Leiden University Medical Center, Leiden, The Netherlands

${ }^{11}$ Department of Rheumatology, Diakonhjemmet Hospital, Oslo, Norway

${ }^{12}$ Department of Clinical Epidemiology, Leiden University Medical Center, Leiden, The Netherlands

Correction notice This article has been corrected since it first published. The article type has been changed from 'Review' to 'Original article'.

Acknowledgements Images from the HOSTAS study were provided by the Department of Radiology and Rheumatology of the LUMC (Leiden, the Netherlands). We acknowledge W Damman and R Liu for acquisition of the images. Images from the Nor-Hand study were provided by the Diakonhjemmet Hospital (Oslo, Norway).

Contributors FPBK and MK were responsible for the conception of the study. FPBK and IKH were responsible for data acquisition. FPBK, CGP, MR, JLB, IKH and MK were responsible for data analysis, interpretation and drafting of the manuscript. All authors critically revised the manuscript and approved the final version.

Competing interests None declared.

Provenance and peer review Not commissioned; externally peer reviewed.

Data sharing statement FPBK and MK have access to all data, and these are available upon request.

Open Access This is an Open Access article distributed in accordance with the Creative Commons Attribution Non Commercial (CC BY-NC 4.0) license, which permits others to distribute, remix, adapt, build upon this work non-commercially, and license their derivative works on different terms, provided the original work is properly cited and the use is non-commercial. See: http://creativecommons.org/ licenses/by-nc/4.0/

(c) Article author(s) (or their employer(s) unless otherwise stated in the text of the article) 2018. All rights reserved. No commercial use is permitted unless otherwise expressly granted.

\section{REFERENCE}

1. Kroon FPB, Conaghan PG, Foltz V, et al. Development and reliability of the OMERACT thumb base osteoarthritis magnetic resonance imaging scoring system. J Rheumatol 2017;44:1694-8. 


\section{Correction: Atlas for the OMERACT thumb base osteoarthritis MRI scoring system (TOMS)}

Kroon FPB, Peterfy CG, Conaghan PG, et al . Atlas for the OMERACT thumb base osteoarthritis MRI scoring system (TOMS). RMD Open 2018;4:e00583.

This article has been corrected since it first published. The article type has been changed from 'Review' to 'Original article'.

Open Access This is an Open Access article distributed in accordance with the Creative Commons Attribution Non Commercial (CC BY-NC 4.0) license, which permits others to distribute, remix, adapt, build upon this work non-commercially, and license their derivative works on different terms, provided the original work is properly cited and the use is non-commercial. See: http://creativecommons.org/licenses/by-nc/4.0/

(c) Article author(s) (or their employer(s) unless otherwise stated in the text of the article) 2018. All rights reserved. No commercial use is permitted unless otherwise expressly granted.

RMD Open 2018;4:e000583corr1. doi:10.1136/rmdopen-2017-000583corr1

A) Check for updates 